\title{
B.P. Hasdeu - ipostază a „specialistului român”
}

\author{
Cristina Bezea ${ }^{\star}$ \\ Facultatea de Litere, Universitatea „Alexandru Ioan Cuza”, Bd. Carol I 11, 700506 Iași, România
}

Despre articol
Istoric:
Primit 23 august 2021
Acceptat 3 septembrie 2021
Publicat 12 decembrie 2021
Cuvinte-cheie:
filologie
istoria limbii
diacronie

\begin{abstract}
Rezumat
Menirea oricărui specialist, indiferent de sfera abordată, este aceea de a servi năzuințelor de dezvoltare științifică și culturală a poporului său. Însă, în cadrul amplului proces de căutare a adevărului științific, posibilitatea întrevăzută de unii savanți pentru îndeplinirea acestui țel este polemica științifică, manifestată deseori printr-un duel aprins al cuvintelor.

Acest articol urmărește confruntarea unora dintre cele mai reprezentative figuri ale lingvisticii românești, confruntare desfășurată pe tărîmul nesfirșit al ideilor. Uzînd de arme precum ironia usturătoare, umorul și sarcasmul, Alexandru Philippide conturează o nouă ipostază a „specialistului român”, de data aceasta concretizată în persoana lui Bogdan Petriceicu Hasdeu.
\end{abstract}

\section{Introducere}

Personalitate remarcabilă a culturii românești, filologul și omul de cultură Bogdan Petriceicu Hasdeu se situează după Dimitrie Cantemir și Heliade Rădulescu, împreună cu Maiorescu și Eminescu printre figurile emblematice a căror operă a învins acțiunea măcinătoare a timpului. Reprezentînd tipologia savantului de formație enciclopedică, prin vastitatea preocupărilor sale, Hasdeu dovedește o sete neobosită de cunoaștere și adevăr, izbutind să devină un pionier în numeroase domenii de activitate.

Avînd un „temperament extrem de sensibil și vehement” (Sacerdoțeanu, 1942, p. 8), dotat cu o fire prin excelență polemică, „scriitorul și savantul nu poate crea fără să nu se confrunte cu cei din jur” (Drăgan, 1972, p. 243). Încredințat că pe tărîmul științei polemica oferă întotdeauna două avantaje: 1. ajută la definitiva limpezire a unor probleme, pînă atunci mai mult sau mai puțin controversate; 2 . dezvălește și arată la lumină, adesea fără apel sau recurs la casațiune, superficialitatea unuia dintre luptători (Hasdeu, 1872, p. 21), opera sa, cu precădere cea științifică, trăiește prin izbucnirile ei polemice.

Întrucit „demonul polemicii a fost o constantă a personalității hasdeene” (Goia, 2014, p. 28), acesta intră în confruntare pe tărîmul ideilor cu mulți dintre contemporanii săi. $\mathrm{O}$ astfel de bătălie a cuvintelor poartă Hasdeu cu alt lingvist de seamă al epocii, Alexandru Philippide, un ascuțit observator al epocii sale, devenind, în accepțiunea acestuia, o ipostază a „specialistului român”.

Privită la o distanță de un secol, această polemică ce reunește două personalități care prin contribuțiile și activitatea lor au lămurit și au făcut cunoscute problemele limbii române, poate părea desuetă, însă aportul adus științei în urma acestui schimb de idei, le asigură celor doi lingviști recunoștința cercetătorilor pentru totdeauna.

\section{2. „Specialistul român”}

În încercarea de a clădi un climat științific prielnic dezvoltării culturii românești, beneficiind de efectele dezvoltării culturale și științifice europene ale secolului al XIX-lea, profesorul Alexandru Philippide dorește să imprime trăinicie și rigoare activității științifice. Constatînd că „savantul român oglindește societatea românească. Cum e turcul, şi pistolul. Cum e țara și savantul” (Philippide, 1907, p. 68), lingvistul ieșean este nemulțumit de comportamentul și rezultatele științifice ale învățaților români. Conștient de

*Adresă de corespondență: cristina_pupaza@yahoo.com. 
forța sa intelectuală, Philippide încearcă să impună în viața publică și culturală a țării modelul unui savant desăvîrșit. Astfel, polemica sa este orientată cu precădere asupra condiției intelectualului atît în cultura română, cît și în cea universală.

Sintagma „specialistul român” a fost impusă de lingvistul ieșean prin articolele și studiile sale de natură polemică, în special Specialistul romîn, Un specialist romîn la Lipsca și Cum se apără specialistul român. Această categorie, a specialiștilor români, înfloritoare după 1866, însumează o serie de savanți improvizați, intelectuali pedanți, din rîndul celor „care mînjesc hîrtiea” (Philippide, 1907, p. 81), caracterizați de strîmta specializare și îngustimea orizontului.

Atitudinea critică a lui Philippide schițează figura „specialistului român”, figură ce preia, pe rînd, imaginea unor personalități contemporane acestuia, precum Bogdan Petriceicu Hasdeu, Sextil Pușcariu, Aron și Ovid Densusianu, Heimann Hariton Tiktin, Gustav Weigand, Adolf Tobler etc. Aceștia și alții asemenea lor sunt ridiculizați, iar lucrările le sunt persiflate, uneori chiar desființate, toate acestea realizate cu argumente atent selecționate de ochiul critic al savantului ieșean.

\subsection{B.P. Hasdeu - ipostază a "specialistului român"}

Modelul „specialistului român” creionat de către Philippide este întruchipat exemplar de Bogdan Petriceicu Hasdeu. Nume sonor al epocii sale, Hasdeu era înzestrat cu două mari calități: „erudiția înspăimântătoare și verbul necruțător” (Drăgan, 1972, p. 84), calități care i-au atras, pe lîngă faimă și „duşmănii neîmpăcate chiar de la cei care, prin comunitatea preocupărilor, ar fi trebuit să fie cei mai apropiați de Hasdeu, ca Alexandru Philippide" (Poghirc, 1968, p. 229).

Astfel, o mostră din cel de-al doilea tip de polemică identificat de Simona Șova la Philippide (Șova, 2013, p. 70) ${ }^{1}$, adresată teoriilor lui Hasdeu referitoare la influența substratului dacic asupra limbii române, identificăm la sfirș̦itul Principiilor (Philippide, 1894, p. 288-307). Pasajul a fost publicat de junimiști în articolul $D$-l Hasdeu și «Istoria limbii române» din „Convorbiri literare” (Philippide, 1895, p. 846869). În nota redacției de la începutul articolului îi sunt recunoscute meritele filologice ale lui Hasdeu, considerat o "personalitate marcantă pe terenul filologiii române” (Philippide, 1895, p. 846), autor al unor teorii și idei originale. Ceea ce i se impută este faptul că „imaginația și spiritul său brilliant, l-a împiedicat de multe ori să vază clar în materialul ce avea de studiat, l-a determinat să prefere construcțiile ingenioase și seducătoare în locul adevărului lipsit de podoabe" (Philippide, 1895, p. 846).

În cadrul acestui articol, Philippide îl acuză pe autorul Cuventelor că și-a însușit părerea nedemonstrată a lui Kopitar, care susținea că românii și albanezii aparțin aceluiași neam, că albaneza este vechea ilirică neatinsă de influența romană, că limba română este cea mai veche dintre limbile romanice, originea ei trebuind căutată cu mult înainte de Traian etc. Cercetarea lui Hasdeu avea ca scop identificarea în limba română a unor cuvinte de origine dacă pornind de la cele comune românei și albanezei, ilustrarea faptului că genitiv-dativul articulat al substantivelor masculine și feminine se formează la fel în română și albaneză, toate acestea pornind de la ipoteza că românii și albanezii au aceeaşi origine etnică și au întrebuințat cîndva aceeași limbă. Pentru a-și susține teoria, lingvistul basarabean stabilește o serie de reguli pe care trebuie să le respecte în vederea cercetării etimologiei unui cuvînt, însă, aşa cum demonstrează Philippide, „este cel d'întîi care nu se ține de dînsele" (Philippide, 1895, p. 859). Demonstrația lui Philippide se bazează pe exemplele oferite de Hasdeu, pe care le dovedește eronate prin aplicarea regulilor stabilite chiar de acesta. De exemplu, în ceea ce privește regula a 11-a: „«a face deosebiri dacă un cuvânt oare-care face parte din sfera mesologică, genealogică ori antropologică, adică dacă este împrumutat din altă limbă, dacă este moștenit de la limba mamă, ori dacă își are origina în natura omenească, ast-fel ca apariția să-i fie posibilă pretutindeni și totdeauna »" (Philippide, 1895, p. 852), Hasdeu greșește atunci cînd „dă o origină

\footnotetext{
${ }^{1}$ Analiza discursurilor polemice ale lui Philippide au evidențiat două modalități distincte de a polemiza: pe de o parte, diatriba generată doar de consemnarea adevărului științific și de dorința de a combate, cu argumente solide, opiniile științifice eronate emise de către lingviști străini și români (vezi polemicile Phillipide-Meyer Lübke, Philippide-Weigand), și pe de altă parte, polemica determinată de nemulțumiri personale cu privire la oamenii de știință români, a căror adevăruri lingvistice erau rodul intuiților și al supozițiilor, nicidecum al cercetării științifice minuțioase (vezi polemicile Philippide-Hasdeu, PhilippidePușcariu).
} 
genealogică sufixului verbal $-u$ din câpâtuésc, gemuésc și sufixului verbal - $u$ din limba albaneză, peșkue, plumbue, pentru că și una și alta din aceste limbi au desvoltat în mod indepedent antropologic (ca să servim și noi de terminologia lui Hasdeu) această formă (pag. 155)” (Philippide, 1895, p. 855).

Nerespectarea propriilor reguli îl determină pe Philippide să constate că întreaga muncă a lui Hasdeu este zadarnică, eforturile sale de a ajunge la concluzii dinainte stabilite, bazîndu-se doar pe metode nedemonstrabile, nu au nicio finalitate.

Ceea ce stîrnește însă revolta lui Philippide este nerespectarea legilor fonetice. Format în atmosfera Școlii neogramatice, Philippide atribuia o importanță primordială foneticii în studiul limbilor, iar respectarea legilor fonetice era esențială pentru acesta în reconstituirea istoriei limbilor și a etimologiei cuvintelor. Dezavuarea argumentelor aduse de Hasdeu în susținerea ipotezei sale continuă prin demonstrarea unor erori ale etimologiilor stabilite de acesta, erori cauzate de nerespectarea legilor fonetice. Iată un exemplu: „Sufixele - mán și -ándru le pune pe sama Dacilor, fără să ia în considerare prefacerea regulată în $\hat{\imath}$ a lui $a$ accentuat urmat de $n$ în cuvintele romane și fără să citeze vre-un exemplu sigur de $a$ acc. urmat de $n$, din cuvinte romane și din aceleaşi împrejurări, neprefăcut în $\hat{\imath}$ (Philippide, 1895, p. 853).

Atitudinea critică față de Hasdeu este generată și de faptul că acesta făcea unele greșeli elementare de fonetică, ce „nu pot fi dar considerate scăpări din vedere” (Philippide, 1895, p. 859), devenind astfel definitoriu pentru tipologia pe care o reprezintă, dar și pentru ,întreaga stare psihologică a țării noastre” (Philippide, 1895, p. 860). Astfel, lingvistul basarabean „explică trecerea lui sglăvoc «prin acomodare fisiologică: consoanele nevibrătoare $s, v, c$ din sglăvoc prefac în nevibrătorul $c$ pe vibrătorul $g$ », și consideră dar pe $v$ ca un sunet la a cărui producție curentul expirator nu trece prin coardele vocale în vibrație, pe cînd în realitate $v$ este tocmai unul dintre suntele vibrătoare" (Philippide, 1895, p. 859).

Savantul ieșean aseamănă pledoaria lui Hasdeu unei „plutiri prin tot felul de plăsmuiri neexacte ale inducțiii, unde te amețești printr'o svînturată primblare de la o limbă la alta” (Philippide, 1895, p. 860), lipsindu-l de orice merite pe autorul acesteia: „Hasdeu întîlnește numai din întîmplare adevărul acolo unde îl întîlnește" (Philippide, 1895, p. 860).

Critica lui Philippide va stîrni, „temperamentul pasionat și combativ al lui Hasdeu” (Macrea, 1954, p. 8), reacția sa concretizîndu-se într-un scurt articol-răspuns intitulat Philippidiotisme din „Revista nouă”. Titlul sugestiv dat de Hasdeu articolului său reflectă pe de o parte tonul abordat de acesta în cadrul dialogului purtat cu Philippide, iar pe de altă parte ironia zdrobitoare a stilului polemic hasdeean. Printr-o sublimă ridiculizare Hasdeu afirmă că adversarul său îndrugă „cai verzi pe pereți” (Hasdeu, 1893, p. 160), jignindu-i, totodată, mîndria prin compararea faptelor sale cu cele ale unui nebun închis la balamuc.

În contextul existenței unor termeni de origine gotică în lexicul românesc, teorie fundamendată de Hasdeu, mai mult pe seama intuiției, Philippide construiește în paginile Originilor un veritabil discurs ironic la adresa acestuia: „Iar Hasdeu în Istoria critică a româniloru, Bucuresci, 1875, p. 297, zice: «Scormonind pretutindeni în paragrafii precedenți și zgîndărind toate coardele și cordițele limbii române, noi nu găsim nici o umbră de necontestaabil gostism, măcar în două optimi ale unei singure vorbe ». Este de prisos să mai adaog la această pretențioasă afirmare că în acei paragrafi precedenți Hasdeu nu scormonise și nu zgîndărise nimic din limba românească!” (Philippide, 2014, p. 355).

Atitudinea ostilă manifestată față de Hasdeu se datorează nu numai spiritului critic pătrunzător al lui Philippide, care nu putea trece peste teoriile neverosimile, deseori fanteziste, vehiculate de acesta, ci și ambianței junimiste, care privea cu ochi critici activitatea științifică a lui Hasdeu (Ivănescu, 1984, p. XI). Polemicile lui Hasdeu cu Maiorescu și junimiștii au fost bine cunoscute în epocă, adversitatea dintre cei doi mari șefi de școală s-a datorat unor „mari deosebiri de temperament, de spirit, de vederi politice și de caracter" (Goia, 2014, p. 41).

În cadrul articolului Specialistul român, Philippide identifică în evoluția savantului român din domeniul filologiei trei faze. Prima fază îi are drept reprezentanţi pe oameni precum: Laurian, Papiu Ilarian, Cipariu, Asachi, Săulescu, Kogălniceanu și Aron Pumnul, toți reuniți prin dorința sinceră de a ști. Operele acestora erau bogate în cuprins, dar fără formă, iar autorii lor „cam seci, au fost ademeniți mai mult de gloriea provenită prin știință decît de știința însăș și au fost mușcați la inimă de șarpele gloriei” (Philippide, 
1907, p. 70), fapt ce a făcut ca în cultura română „să răsară talentele și geniile ca ciupercele” (Philippide, 1907, p. 70). Faza a doua este ilustrată prin persoana lui V.A. Ureche, ale cărui opere au rămas „din fericire nepublicate" (Philippide, 1907, p. 70) și prin cea a lui Hasdeu, despre care, amintind de umorul ironic humuleștean, Philippide afirmă că asemenea altor specialiști de faza a două „o brodia și D-sa cam cu oiștea în gard” (Philippide, 1907, p. 73). Reprezentantul celei de-a treia fază din evoluția specialistului român este Titu Maiorescu, vechi colaborator al lui Philippide, care, în opinia profesorului ieșean, deși avea pretenția de fi militant împotriva formei goale, a considerat-o pe aceasta știință și s-a făcut patronul ei, crescînd sub egida sa „o pleiadă de specialiști români, care au redus știința în țara românească la minimum” (Philippide, 1907, p. 78).

În ceea ce îl privește pe Hasdeu, Philippide mărturisește cu ironie că acesta este „superior tuturor savanților din faza II” (Philippide, 1907, p. 73). Profesorul ieșean subliniază în repetate rînduri că, asemenea specialiștilor din această categorie, savantul basarabean este caracterizat de lipsa unor cunoștințe temeinice: „nu știe din fisiologiea sunetelor nimic” (Philippide, 1907, p. 74), „habar n-are de fisiologiea sunetelor" (Philippide, 1907, p. 74).

Critica lui Philippide se oprește și asupra erudiției pe care Hasdeu o etala cu fiecare ocazie: „răpede răpede D-sa a pus mîna pe toate meșteșugurile științii și a început un foc bengal de nume proprii, citații, noutăţi, reviste, prietenii cu celebrități.... încît a rămas într-adevăr lumea cu gura căscată” (Philippide, 1907, p. 73). O critică aspră a modului în care Hasdeu alege să își expună ideile întîlnim și în următorul pasaj: „Dl. Hasdeu nu știa nimic, ci numai titluri de cărți, citaţii din opere răsfoite, colb zvîrlit în ochii lectorului diletant, adecă forma goală” (Philippide, 1907, p. 76), cu referire la bogăția bibliografică, o trăsătură fundamentală a scrierilor lui Hasdeu, ca ipostază a specialistului român.

\section{Concluzii}

În ciuda faptului că „s-a lăsat uneori sedus de imaginație acolo unde lipseau dovezi materiale evidente” (Macrea, 1954, p. 7), meritele lui Hasdeu în fundamentarea cercetării știinţifice a limbii române sunt incontestabile. Cercetător cu vocație multilaterală, autorul Cuventelor din bătrîni reprezintă una dintre figurile care au dominat trecutul culturii românești, avînd valoroase contribuții în domeniul filologic, istoric, lexicografic etc. Din nefericire, dramele familiale s-au dovedit pentru acesta "un punct foarte vulnerabil, călcîiul lui Ahile" (Munteanu, 1963, p. 41). Astfel, opera izvorîtă din geniul hasdeean a condus, uneori, mai mult la „ipoteze ademenitoare decît la rezultate concrete” (Macrea, 1954, p. 10).

Animozitatea lui Philippide față de Hasdeu, nu poate fi nici pe departe explicată printr-o „ură neîmpăcată”, o ură dezlănțuită de articolul Philippidiotisme, care „punea la punct pretențiile pe atunci nejustificate ale tânărului cercetător” așa cum susține Cicerone Poghirc în monografia dedicată lui Hasdeu (vezi Poghirc, 1968, p. 230). Deși catalogate ca fiind puțin academice și nedrepte (Poghirc, 1970, p. 164), ostilitățile manifestate de către Philippide faţă de savantul basarabean trebuie puse pe seama respectului pentru oameni și pentru cunoaștere. Fiind pătruns de simțul răspunderii față știință, acesta intră în luptă cu savantul „specialist”, în vederea cunoașterii adevărului științific și lămurirea publicului cititor, adevăratul său scop fiind de a proba veridicitatea teoriilor emise.

Importantă pentru ilustrarea esenței polemice a profesorului ieșean, figura „specialistului român” creată în urmă cu mai bine de un secol, configurează un tablou al vulnerabilităţilor oamenilor de știință mult mai viu și mai actual decît poate părea pentru mulți. Analizând viața științifică actuală, un Philippide al zilelor noastre ar descoperi urmași ai specialistului romîn la tot pasul.

\section{Bibliografie}

Drăgan, M. (1972). B. P. Hasdeu, Editura Junimea, Iași.

Goia, V. (2014). Polemica între vocație și diletantism, Editura Școala Ardeleană, Cluj-Napoca.

Hasdeu, B. P. (1872). Cestiuni istorice. Polemica științifică cu d. A. Papiu, în „Columna lui Traian”, III (3), p. 21. 
Hasdeu, B. P. (1893). Philippidiotisme, în „Revista nouă”, 3-4, p. 160. Retipărit în vol. Sarcasm şi ideal, Editura Librăriei Socecu \& Comp., București, 1897, p. 212.

Ivănescu, G. (1984). Alexandru Philippide - teoretician al limbajului, în Al. Philippide, Opere alese. Teoria limbii, ediție îngrijită de G. Ivănescu și Carmen-Gabriela Pamfil, Editura Academiei R.S.R., București.

Macrea, D. (1954). Opera lingvistică a lui Bogdan Petriceicu-Hasdeu, în „Limba română”, III (3), p. 5-21.

Munteanu, G. (1963). B.P. Hasdeu, Editura pentru literatură, București.

Philippide, A. (1894). Istoria limbii române, vol. I. Principii de istoria limbii, Tipografia Națională, Iași.

Philippide, A. (1895). D-l Hasdeu și «Istoria limbii române», în „Convorbiri literare”, XXIX, p. 846-869.

Philippide, A. (1907). Specialistul Romîn. Contribuție la istoriea culturii romînești din secolul XIX, Editura „Vieții romînești”, Iași.

Philippide, A. (2014). Originea românilor, vol. I, ediția a II-a, ediție de Roxana Vieru, prefață de Carmen-Gabriela Pamfil, Editura Universității „Alexandru Ioan Cuza”, Iași.

Poghirc, C. (1968). B. P. Hasdeu lingvist și filolog, Editura Științifică, București.

Poghirc, C. (1970). In legătură cu Hasdeu și cu obiectivitatea științifică, în „Limba română”, XIX (2), p. 153-165.

Sacerdoțeanu, A. (1942). Bogdan Petriceicu-Hasdeu, în „Revista arhivelor”, V, p. 1-10.

Șova, S. (2013). Polemica la Alexandru I. Philippide, în AUI, secțiunea III e, Lingvistică, LIX, p. 65-74. 